\title{
DEVELOPMENT OF A MONITORING METHOD OF HYDROGEN REMOVAL FROM ALUMINUM MELT USING NUMERICAL SIMULATION
}

\author{
Jana SVIŽELOVÁ, Markéta TKADLEČKOVÁ, Karel MICHALEK, Josef WALEK \\ VSB - Technical University of Ostrava, Ostrava, Czech Republic, EU \\ jana.svizelova@vsb.cz
}

https://doi.org/10.37904/metal.2019.959

\begin{abstract}
The use of aluminum alloys in many industrial sectors is still increasing today. Due to its excellent properties, aluminum is widely used, for example, in construction, food, and automotive industries. The increase in the use of aluminum is also accompanied by increasing demands for chemical and metallographic cleanliness of this metal. The presence of unwanted phases in the molten metal can cause changes in final castings properties, such as porosity, corrosion susceptibility, electrical and thermal conductivity, etc. These phases are represented especially by harmful gases and non-metallic inclusions. Although significant progress has been made in the field of metallurgy in recent decades, great attention is still being paid to the optimization of metallurgical processes. Refining technology of aluminum melts is not the exception. Reducing refining time and process intensification often results in significant financial savings. This work is focused on the actual phase of research and development of refining technology of aluminum melt by an inert gas, through numerical modelling in ANSYS Fluent simulation software.
\end{abstract}

Keywords: Metallurgy, aluminum, numerical modelling, ANSYS Fluent

\section{INTRODUCTION}

The presented research is focused on the development of numerical modelling method for a prediction of aluminum refining technology efficiency using ANSYS Fluent which is available in Laboratory RMSTC physical and numerical modelling in Department of Metallurgy and Foundry of Faculty of Materials Science and Technology. Numerical simulations of metallurgical processes are a common part of research as evidenced, for example, by studies [1-4]. However, numerical modelling of the degassing intensity of molten metals is not quite common. The current phase of research is focused on simulations of turbulent flow in refining ladle and also on choice and settings of models intended to catch degassing intensity by an inert gas. Research output will be the unique setting of the numerical model which will provide correct results of refining process simulations and will save money and time related to the need for construction of physical models or pilot plants.

The aim of aluminum melt refinement is impurities removal, which is represented especially with harmful gasses $(\mathrm{H})$ and nonmetallic inclusions [5-7]. Currently, a few types of technologies are used for aluminum melt refinement. In this paper, the procedure of aluminum melt refining by inert gas blow through the rotational submersible device (see Figure 1) was studied. The submersible device consists of a hollow rotor by which the inert gas is blown into the melt in ladle. Flow on a melt surface and size of phase interface melt-atmosphere is influenced by one or two breakwaters. The purpose of breakwaters is to minimize ripple on a melt surface during inert gas blowing and rotor rotation and thereby limitation of risk of hydrogen absorbing from surroundings. Inert gas flow is distributed in the melt due to the rotation of the rotor.

To capture the intensity of hydrogen removal from aluminum melt with changing some process parameters (rotational speed and type of rotor), numerical simulations were carried out. The object of CFD numerical modelling was a water physical model of refining ladle (see Figure 1, see ref. [8]). Comparison of results from physical modelling provides a unique opportunity to verify numerical model results. In the physical model, 
harmful hydrogen is replaced by oxygen. Oxygen is removed by inert gas and its concentration is monitored by two optical probes.

\section{DESCRIPTION OF MODELED PHENOMENA AND SIMULATION PROCEDURE}

Aluminum melt refinement by the submersible device is a complicated process which includes several partial processes: turbulent flow in the ladle, free surface movement, inert gas inlet and floating of bubbles from the melt, diffusion of hydrogen to inert gas during floating of bubbles. Within numerical simulations is impossible to simulate all these partial processes simultaneously. At best, a significant extension of computational time can occur. Probably, the calculation convergence would not be achieved at all. Therefore, it is good to divide it into several stages, which are in terms of numerical modelling represent by:

- $\quad$ Steady State calculation of turbulent flow in the ladle, without considering the phases;

- Transient calculation of turbulent flow in the ladle with phase considerations and calculation of free surface of water behavior;

- $\quad$ Simulation of the residence time of tracer in the model liquid;

- $\quad$ Simulation of argon bubbles formation and spreading in the model liquid.

The difference between real and numerically modelled process relates especially to the diffusion of harmful gas to refining gas. To the description of the removal of harmful gas by numerical simulation, the determination of the residence time of the tracer and argon bubbles in the ladle is applicable [9]. Another effort will be to find a correlation between these parameters and parameters of the physical model, such as the amount of blown inert gas or time to reach the desired oxygen concentration in the water. This method does not exactly define the actual time to reach minimal content of oxygen in the water, but it is possible to define degassing efficiency at given boundary conditions.

In the first stage of turbulent flow simulations, a two-phased setting of computation was tested. The first phase was focused on steady state (time independent) calculations with constant rotational speed, without considering phases. The results of this calculation were used as an initial solution in the second phase, i.e. the transient (time-dependent) flow calculation with the computation of free surface behavior.

The turbulent SST $\mathbf{k}-\boldsymbol{\omega}$ model was used to steady-state calculation of flow in the ladle. This model contains equations for calculation of flow and turbulent quantities - the turbulent kinetic energy $k$ and the specific dissipation of turbulent kinetic energy $\omega[10,11]$. The turbulent model was complemented by an implicit formulation of the multiphase Volume of Fluid (VOF) model. The implicit formulation of the VOF model is more suitable for steady flow simulations. The VOF model is intended primarily to simulations of unsteady flow. In the case of steady flow, only problems independent on initial conditions can be calculated. This is not the case of the aluminum refining process $[10,11]$. Free surface movement is dependent on the initial condition, namely the water level in the reactor. To get around this problem, the steady flow was calculated with only one base phase - water.

The time-dependent flow was modelled by the same models as were used in the case of steady flow, with some certain modifications. As mentioned, results of steady flow and turbulent field for one phase were used as the initial solution. These results were additionally complemented by volumes filled by water and air. Because it was the time-dependent solution, the VOF model could be used in a full range $[10,11]$. For transient calculations, the correct choice of a time step is necessary because the time step influences the computational time and convergence of the calculation. Thanks to the use of the initial solution, the time step can be chosen in $10^{-4} \mathrm{~s}$. Also, thanks to the use of initial solution convergence of calculation, the solution became faster in every time step and overall computational time was reduced.

Refining efficiency of inert gas on oxygen removal from the water was verified by monitoring tracer concentration change in time and by time to reach a homogenous concentration of the liquid. The principle of 
calculation of concentration change is definition passive scalar [10,11]. The Species Model was used to calculate the passive scalar. Results of this calculation are time-dependent concentration curves through which it is possible to evaluate the rate of oxygen concentration spreading in the ladle.

Movement and transport of argon bubbles can be described by the calculation of discrete phases. This method realistically describes the movement of the argon bubbles in the ladle. Bubbles transport can be monitored only in the liquid phase (water) and after the escape from water can be each bubble deleted by user-defined function $[10,11]$. Complemented of the model by this function, the average residence time of bubbles in the ladle can be estimated, also the number and volume fraction can be established.

\section{NUMERICAL MODELLING PROCEDURE}

\subsection{Geometry and setting of initial and boundary conditions}

As mentioned, the subject of research is the physical model of real ladle intended to aluminum refining by inert gas (see Figure 1). Due to the possibility to verify results of the numerical model, a computational geometry was constructed based on the geometry of the physical model. Numerical model geometry includes each component of refining device, i.e. the rotor and two breakwaters which reduces the formation of a typical vortex and the turbulent behavior on the surface of the water. The geometry of the numerical model represents the internal volume of the ladle (see Figure 2).
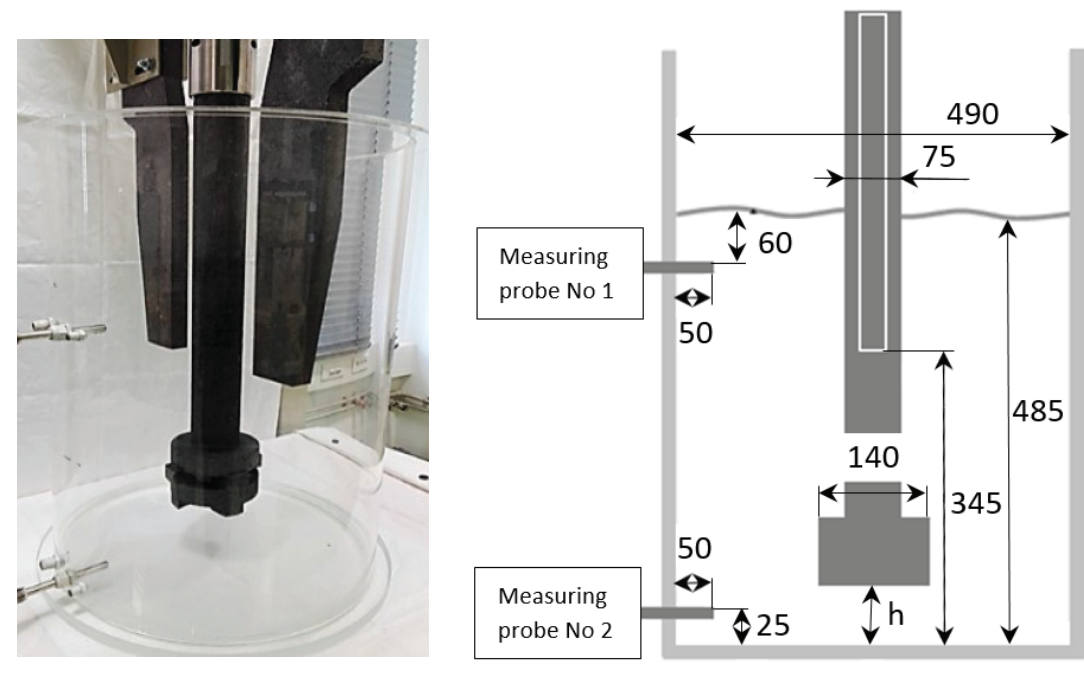

Figure 1 Physical model of refining device and scheme of physical model [8]

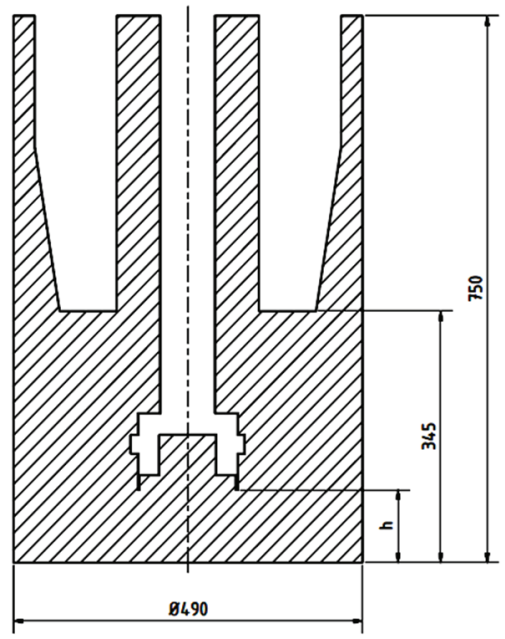

Figure 2 Internal geometry of refining device

Due to the possibility of comparison of numerical results with physical modelling, water was also considered for numerical modelling. In the first stage of simulations, also free surface behavior was calculated by the VOF model. It was necessary to define the properties of water and the surrounding air. Physical properties of both Table 1 Properties of model media phases are listed in Table 1.

\begin{tabular}{|c|c|c|}
\hline Medium & $\begin{array}{c}\text { Density } \\
\left(\mathrm{kg} \cdot \mathrm{m}^{-3}\right)\end{array}$ & $\begin{array}{c}\text { Dynamic viscosity } \\
\left(\mathrm{kg} \cdot \mathrm{m}^{-1} \cdot \mathrm{s}^{-1}\right)\end{array}$ \\
\hline Air & 1.225 & $1.79 \cdot 10^{-5}$ \\
\hline Water & 998 & $10.0 \cdot 10^{-4}$ \\
\hline
\end{tabular}

During this study, the homogenization effect of two different types of the rotor, designated as F2-A and J8, was observed. For purposes of evaluation of the homogenization effect of rotors with different rotational speeds 
(350 and $500 \mathrm{rpm}$ ), 4 variants of numerical simulations were defined. A distance of rotor from the bottom of the ladle was $100 \mathrm{~mm}$. Parameters of modelled variants are listed in Table 2.

Table 2 Settings of suggested variants

\begin{tabular}{|c|c|c|c|c|}
\hline Variant & Rotor type & $\begin{array}{c}\text { Number of } \\
\text { breakwaters }\end{array}$ & $\begin{array}{c}\text { Rotational speed } \\
(\mathrm{rpm})\end{array}$ & $\begin{array}{c}\text { Rotor immersion } \\
(\mathrm{mm})\end{array}$ \\
\hline 1a & F2-A & 2 & 350 & 100 \\
\hline 1b & F2-A & 2 & 500 & 100 \\
\hline 2a & J8 & 2 & 350 & 100 \\
\hline 2b & J8 & 2 & 500 & 100 \\
\hline
\end{tabular}

\section{RESULTS AND DISCUSSION}

\subsection{Flow field}

Figure 3 shows a comparison of path lines obtained by the numerical model with the results of physical modelling. To present the results of variant $1 \mathrm{~b}$ and $2 \mathrm{~b}$ (with $500 \mathrm{rpm}$ ) were selected. The flow field of variants $1 a$ a 2a (with $350 \mathrm{rpm}$ ) is similar but in case of variants with $500 \mathrm{rpm}$ is better observable. As trace particles for flow observation in the physical model, bubbles of argon blown into the water through a hollow rotor were used. As can be seen, the shape of the rotor F2$A$ induces flow directed at the ladle wall at a certain angle. Also in case of rotor $\mathrm{J} 8$, a mainstream is observed which is directed

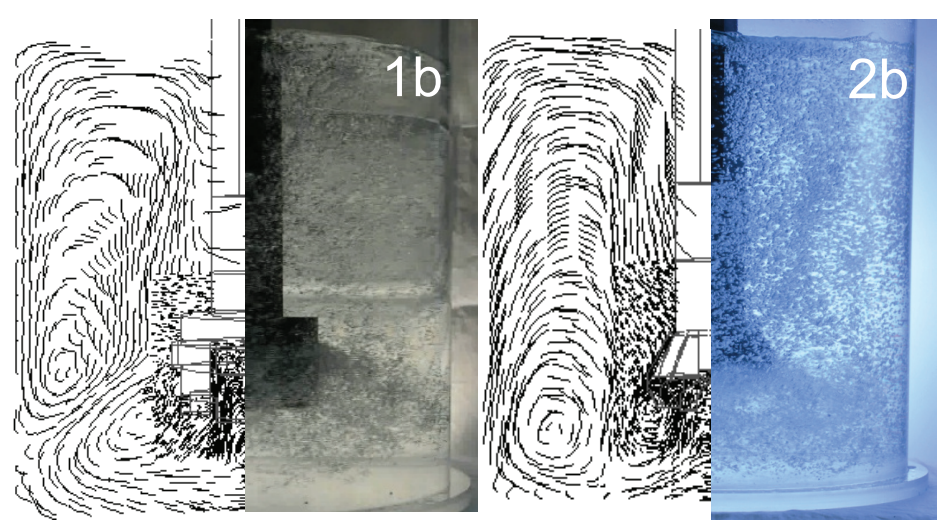

Figure 3 Flow field in reactor - comparison of physical and numerical model results towards the bottom of the ladle. It is clear from the physical model results that the mainstream disperses the blown gas bubbles into the bottom of the ladle from where they float towards the surface. A very similar pattern can be observed on the numerical model results.

\subsection{Homogenization time}

A change in tracer concentration in the ladle was simulated by Species Model. Tracer concentration was monitored at two levels, corresponding to the position of the optical probes on the physical model (see Figure 1). Result of the calculation was the concentration curves showing the character of the RTD curves measured by the conductivity probes on the physical model as found in comparison with the literature [9]. The concentration curves obtained by the numerical simulation for the upper and lower monitor are shown in Figure 4. For this purpose, the homogenization time was defined as the earliest time when the tracer concentration in the monitors deviates by less than $1 \%$ of the final concentration of tracer. The calculated homogenization times with the refining times (reaching the desired oxygen concentration of $0 \mathrm{ppm}$ ), measured by the optical probes on the physical model, are shown in Table 3. It can be seen that the tracer concentration is earlier stabilized at the bottom of the reactor, due to rotor immersion (100 $\mathrm{mm}$ from the bottom) and flow in the rotor area (see Figure 2), which faces the bottom of the reactor for both types of rotors. Concentration curves show that in the case of the F2-A rotor there is an earlier concentration of tracer in the reactor. This is also confirmed by the overall retention times, which are in line with the refining times on the physical model. 


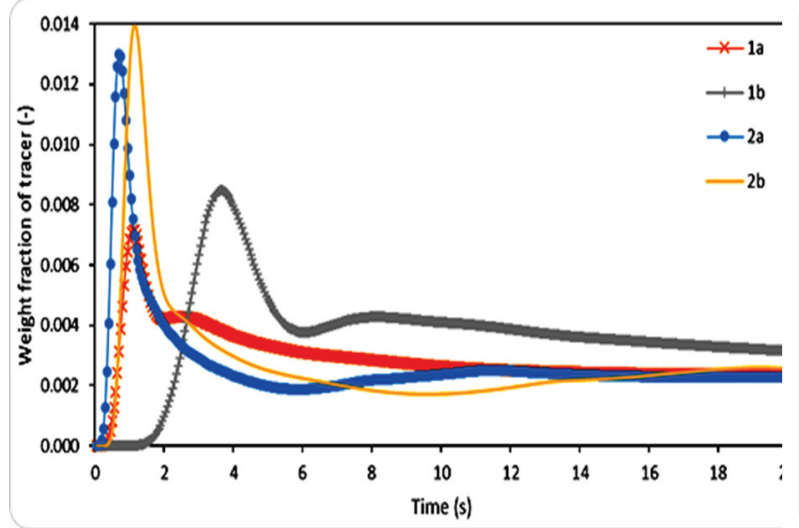

a) Bottom monitor

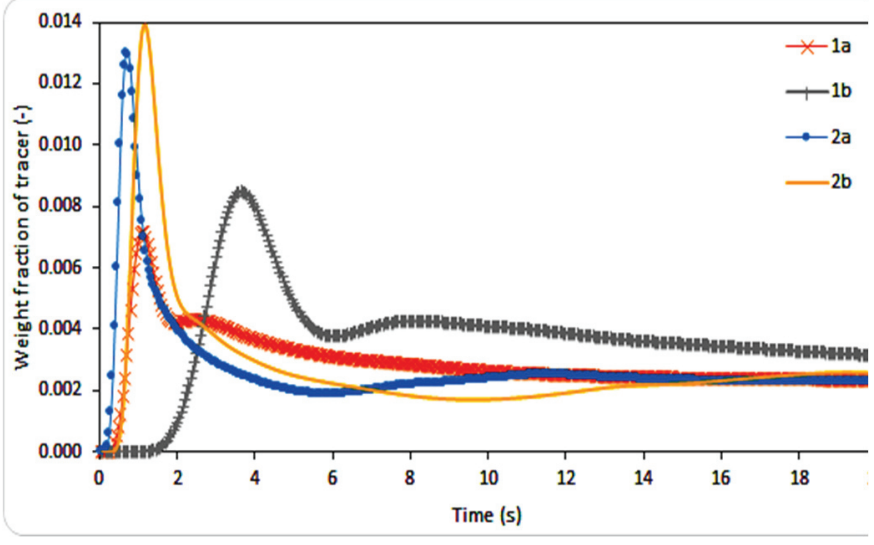

b) Upper monitor

Figure 4 Concentration curves obtained by numerical simulation

Table 3 Homogenization times obtained by numerical simulation

\begin{tabular}{|l|c|c|c|c|c|c|}
\hline \multirow{2}{*}{ Variant } & \multirow{2}{*}{$\begin{array}{c}\text { Rotor } \\
\text { type }\end{array}$} & \multirow{2}{*}{$\begin{array}{c}\text { Rotational } \\
\text { speed (rpm) }\end{array}$} & \multicolumn{2}{|c|}{$\begin{array}{c}\text { Homogenization time in each } \\
\text { monitor (s) }\end{array}$} & $\begin{array}{c}\text { Total } \\
\text { homogenization } \\
\text { time (s) }\end{array}$ & $\begin{array}{c}\text { Refining time in } \\
\text { physical model } \\
\text { (min) }\end{array}$ \\
\cline { 4 - 5 } & & Bottom monitor & Upper monitor & 16 & 15.9 \\
\hline $1 \mathrm{a}$ & F2-A & 350 & 16 & 8.85 & 10.5 & 10.1 \\
\hline $1 \mathrm{~b}$ & F2-A & 500 & 10.5 & 5.7 & 17.8 & 21.8 \\
\hline $2 \mathrm{a}$ & J8 & 350 & 15.7 & 17.8 & 12.4 & 12.2 \\
\hline $2 \mathrm{~b}$ & $\mathrm{~J} 8$ & 500 & 9.2 & 12.4 & & \\
\hline
\end{tabular}

\section{CONCLUSIONS}

This paper presents the development of the method of numerical modelling of the molten aluminum refining process with inert gas. The subject of the research was the refining device, consisting of a ladle, breakwaters and rotor. In the initial phase, numerical simulations were carried out using parameters of the physical model, which provides the possibility to verify the results of simulations. Aluminum melt refining with inert gas is a complex process consisting of several partial processes. Therefore, this technology cannot be described by a single numerical model. For the purposes of the numerical modelling, the process was divided into sub-stages according to the character of available numerical models:

- $\quad$ Steady and transient calculation of turbulent flow - modeled by turbulent SST k- $\omega$ Model with multiphase VOF model for free surface description. The result is flow fields in the reactor and a visualization of the waves at the reactor level.

- $\quad$ Simulation of tracer residence time in the water - modelled by the Species model. The result is RTD curves of tracer to help capture the refining intensity depending on boundary conditions.

- Simulation of the inert gas blowing (spread bubbles in the water volume) - it is assumed that Discrete Phase Model will be used in combination with the user function for bubble deleting from the level of the water.

The current results of the research can be summarized into following conclusions:

- $\quad$ The flow results from numerical model are in a good agreement with the physical model results.

- The presence of the rotor largely influences the nature of the flow in the reactor. The rotor induces a flow that is directed to the bottom of the reactor. This flow catches the incoming argon stream and disperses it into bubbles. 
- Homogenization intensity of the water in the reactor was evaluated by RTD curves calculated by the numerical model. It was found that the intensity of homogenization is dependent on the rotational speed of rotor. Shorter residence times were detected at higher rotational speeds, consistent with the results of physical modeling.

- $\quad$ Also, homogenization intensity varies depending on the rotor shape. The F2-A rotor has a more intense homogenizing effect than the J8 rotor. This finding is consistent with the physical model in which shorter refining times are achieved for the F2-A rotor.

The next phase of the research will be focused on the numerical description of inert gas blowing into the reactor. The aim will be to find suitable parameters for comparison with the results of the physical model. These parameters will be used to the correct description of the refining intensity by the numerical model.

\section{ACKNOWLEDGEMENTS}

The work was created under the support of the Czech Ministry of Industry and Trade within the frame of the programme TRIO in the solution of the projects reg. No. FV10080 "Research and Development of Advanced Refining Technologies of Aluminum Melts for Increase in Product Quality". This paper was created with the financial support from the Moravian-Silesian Region budget under the program "Support for Science and Research in the Moravian-Silesian Region" (RRC/10/2017), Student Grant Competition No. SP2019/148 and SP2019/43. This work was supported by The Ministry of Education,

Youth and Sports from the Large Infrastructures for Research, Experimental Development and Innovations project „IT4Innovations National Supercomputing Center - LM2015070“.

\section{REFERENCES}

[1] POLA, A., GELFI, M. and LA VECCHIA, G. M. Comprehensive numerical simulation of filling and solidification of steel ingots. Materials. 2016. vol. 9, iss. 9. DOI: 10.3390/ma9090769.

[2] SVIŽELOVÁ, J., TKADLEČKOVÁ, M., MICHALEK, K. and STROUHALOVÁ, M. Influence of casting speed on centerline porosity formation in continuously cast round steel billets. In METAL 2017: $26^{\text {th }}$ International Conference on Metallurgy and Materials. Ostrava: TANGER Ltd., 2017. ISBN 978-80-87294-73-4.

[3] WARKE, V. S., TRYGGVASON, G. and MAKHLOUF, M. M. Mathematical modeling and computer simulation of molten metal cleansing by the rotating impeller degasser: Part I. Fluid flow. J Mat Pro Tech. 2005. vol. 168, no. 1, pp. 112-118. DOI: 10.1016/j.jmatprotec.2004.10.017.

[4] REIDLER, M., MICHELIC, S. and BERNHARD, C. Numerical simulation and experimental validation of the formation of shrinkage cavity during solidification of steel. In METAL 2016: $25^{\text {th }}$ International Conference on Metallurgy and Materials. Ostrava: TANGER. 2016. pp. 97-103

[5] SIGWORTH, G. K. A Scientific Basis for Degassing Aluminum. AFS Transactions. 1987. pp. 73-78. ISBN 087433-106-4

[6] GOMÉZ, E. R., ZENIT, R., RIVERA, C.G. and TRÁPAGA, G., RAMÍREZ-ARGÁEZ M. A. Mathematical modeling of fluid flow in a water physical model of an aluminum degassing ladle equipped with an impeller-injector. Metal Mater Trans B. 2013. vol. 44B, pp. 423-435. DOI: 10.1007/s11663-012-9774-8.

[7] HERNÁNDEZ-HERNÁNDEZ, M., CAMACHO-MARTÍNEZ J. L. and GONZÁLEZ-RIVERA C., RAMíREZ-ARGÁEZ M. A. Impeller design assisted by physical modeling and pilot plant trials. J Mat Pro Tech. 2016. vol. 236, pp. 1-8. DOI: 10.1016/j.jmatprotec.2016.04.031.

[8] MICHALEK, K., SOCHA, L., GRYC, K., TKADLEČKOVÁ, M., SATERNUS, M. and PIEPRZYCA, J., MERDER, T. Physical modelling of degassing process at blowing of inert gas. Arch. Metal. Mater. 2018. vol. 63, iss. 2, pp. 978992. DOI: $10.24425 / 122432$.

[9] SATERNUS, M. Determination of RTD curves for aluminum refining process conducted in batch reactor - Physical modelling. Arch. Metal. Mater. 2018. vol 63, no 4, pp. 1909-1914. DOI: 10.24425/amm.2018.125123

[10] ANSYS Inc. Fluent 19.2 - ANSYS Fluent, Release 19.2: Users Guide.

[11] ANSYS FLUENT. Tutorial 16. Using the VOF Model. ANSYS Inc, 2005. 